\title{
Research Article \\ Effect of Temperature and Catalyst Concentration on Polyglycerol during Synthesis
}

\author{
Carolina Ardila-Suárez, ${ }^{1}$ Diana Rojas-Avellaneda, ${ }^{1,2}$ and Gustavo E. Ramirez-Caballero ${ }^{1,3}$ \\ ${ }^{1}$ Grupo de Investigación en Polímeros, Escuela de Ingeniería Química, Universidad Industrial de Santander (UIS), \\ Bucaramanga, Colombia \\ ${ }^{2}$ Grupo de Investigación en Materiales, Afaltos y Mezclas Asfálticas para Pavimentos Flexibles, Corasfaltos, \\ Piedecuesta, Colombia \\ ${ }^{3}$ Centro de Investigaciones en Catálisis, Escuela de Ingeniería Química, Universidad Industrial de Santander (UIS), \\ Bucaramanga, Colombia
}

Correspondence should be addressed to Gustavo E. Ramirez-Caballero; gusramca@uis.edu.co

Received 16 June 2015; Revised 13 September 2015; Accepted 15 September 2015

Academic Editor: Yu Wang

Copyright (C) 2015 Carolina Ardila-Suárez et al. This is an open access article distributed under the Creative Commons Attribution License, which permits unrestricted use, distribution, and reproduction in any medium, provided the original work is properly cited.

Morphology, molecular weight, polydispersity, functionality, and thermal properties are important characteristics when using polyglycerol as a building block in the development of materials for industrial applications such as hydrogels, surfactants, asphalts additives, cosmetics, pharmaceutical, biomedical, and drug delivery systems. In this study several experimental techniques are used to understand the effect of process variables during synthesis in the catalyzed etherification of glycerol, a coproduct of biodiesel industry. Biobased polyglycerol is a high-valued product, which is useful as building block material because of its remarkable features, for instance, multiple hydrophilic groups, excellent biocompatibility, and highly flexible aliphatic polyether backbone. A connection between polyglycerol characteristics and process variables during synthesis allows the control of glycerol polymerization through reaction conditions. We show that temperature and catalyst concentration can be tuned with the aim of tailoring fundamental polyglycerol parameters including molecular weight, polydispersity, morphology, and functionality.

\section{Introduction}

Polyglycerol obtained from direct catalytic etherification of glycerol is a biobased polymer used as a building block for several applications, such as hydrogels [1-3], emulsifiers $[4,5]$, catalyst supports [6], and biomedical applications [79]. Industrial and academic interest on glycerol as a raw material for polyglycerol synthesis are based on environmental and economic aspects. This is because a biobased monomer is used for sustainable polymer production; and producing a value-added product from a coproduct from the biodiesel industry contributes to the transformation of this industry into a biorefinery [10]. Synthesis of polyglycerol is currently gaining importance due to its remarkable features including flexible polyether backbone, biocompatibility, and high number of hydrophilic functional groups, which increases polyglycerol versatility and enables the production of complex polymeric structures. Properties of polyglycerolbased materials are highly influenced by polyglycerol morphology, functionality, molecular weight, polydispersity, and thermal properties [11]. Control of glycerol polymerization to selectively produce desired polyglycerol materials with specific characteristics is a scientific challenge that might be addressed by tuning synthesis conditions.

Polyglycerols can be produced from various raw materials and polymerization methods; for instance, glycidol and glycerol carbonate react via one-step anionic ring-opening polymerization [12,13], and glycerol reacts via step-growth polymerization [14]. Several studies have reported the catalytic oligomerisation of glycerol using homogeneous and heterogeneous acid and base-catalyzed etherification $[15,16]$. Most of the reaction products from these catalytic studies are 
low molecular weight oligomers. An exception is the reaction with sulfuric acid homogeneous catalyst which yields relatively high molecular weight polyglycerols [14]. A previous study on the morphology of glycerol etherification derivatives conducted with ${ }^{13} \mathrm{C}$ NMR reported carbon assignments for linear, branched, and cyclic structures [17]. Results of polyglycerol ${ }^{13} \mathrm{C}$ NMR spectroscopy showed that homogeneous acid-catalyzed polymerization of glycerol at high temperatures favors the occurrence of branched structures [14]. To our knowledge, there are no previous reports on the effect of catalyst concentration on polyglycerol morphology produced from glycerol or on the combined effect of temperature and catalyst concentration on polyglycerol properties.

In this work, polyglycerol is obtained from glycerol by a step-growth polymerization reaction using sulfuric acid as catalyst. The effect of tuning temperature and catalyst concentration during synthesis conditions on the parameters that affect polyglycerol morphology, hydroxyl number, molecular weight, polydispersity, functionality, and thermal properties were studied. Our goal is to provide guidelines for the polyglycerol synthesis from glycerol yielding specific product characteristics by varying temperature and catalyst concentration during synthesis. The experimental strategy performed in this study was based on a combinatorial experiment with temperature and catalyst concentration of synthesis as factors. This approach allows considering possible interactions between factors. The techniques used include matrix-assisted laser desorption and ionization time-of-flight spectrometry (MALDI-TOF), nuclear magnetic resonance spectroscopy (NMR), and differential scanning calorimetry analysis (DSC). This paper is organized as follows: first, materials, reaction procedure, and polymer characterization techniques are described; second, results of infrared spectroscopic analysis (FT-IR) of synthesized polyglycerol from glycerol are discussed; and third, the analysis of results is presented. Finally, conclusions of the main findings are reported.

\section{Experimental}

2.1. Materials. Materials used for the synthesis were obtained from different vendors: glycerol (85\%), sulfuric acid (95\%), phenolphthalein indicator, and sodium hydroxide (99\%) were purchased from Merck; acetic anhydride was obtained from Carlo Erba and pyridine (9.5\%) from Mallinckrodt.

2.2. Reaction Procedure. Polymerization reactions were carried out in $50 \mathrm{~mL}$ closed glass reactor in an inert environment (nitrogen atmosphere). Water was continuously removed from the reaction mixture with a vacuum pump. Glycerol $(20 \mathrm{~mL})$ polymerization reaction temperature was varied from $130^{\circ} \mathrm{C}$ to $170^{\circ} \mathrm{C}$ with a heating bath control. Catalyst concentration was modified from $1.5 \%(\mathrm{w} / \mathrm{w})$ to $5.2 \%$ $(\mathrm{w} / \mathrm{w})$. All the reactions were carried out at 24 inches of $\mathrm{Hg}$. Polymerization products were neutralized with a $\mathrm{NaOH}$ $0.1 \mathrm{~N}$ solution and dried at $80^{\circ} \mathrm{C}$ for $24 \mathrm{~h}$ without further purification process.
2.3. Polymer Characterization. Polymerization reaction products were analyzed using Fourier transform infrared spectroscopy (FTIR) to identify functional groups. Infrared spectra were obtained in transmittance mode in a Thermo Scientific Spectrometer (Nicolet 1550 FT-IR).

Hydroxyl numbers were calculated following the ASTM D 4274-11 method. Polymer samples were acetylated with an acetic anhydride-pyridine solution. The unreacted acetylation reagent was hydrolyzed with water and the acetic acid titrated with $0.5 \mathrm{~N}$ sodium hydroxide solution. The hydroxyl content was calculated from the difference in titration between the acetic anhydride-pyridine solution used as a blank and sample solutions.

Molecular weight distributions of different reaction products were obtained using MALDI-TOF-MS measurements performed with a Bruker Reflex mass spectrometer, equipped with a nitrogen laser delivering 3 ns laser pulses at $337 \mathrm{~nm}$. Recrystallized $\alpha$-cyano-4-hydroxycinnamic acid $(10 \mathrm{mg} / \mathrm{mL})$ in $30: 70 \%(\mathrm{v} / \mathrm{v})$ acetonitrile/water containing $0.1 \%(\mathrm{v} / \mathrm{v})$ trifluoroacetic acid (TFA) was used as the matrix. Sodium chloride solution was used as cationization agent. Polymer samples were dissolved in water to a final concentration of $10 \mu \mathrm{g} / \mathrm{mL}$. An aliquot of the matrix $(0.8 \mu \mathrm{L})$ was applied to a multistage target until solvent evaporation; subsequently, $0.1 \mu \mathrm{L}$ of cationization agent and $0.2 \mu \mathrm{L}$ of sample were added.

Polymer morphology analyses were performed using ${ }^{13} \mathrm{C}$ NMR quantitative spectra taken on a Bruker Ultrashield $400 \mathrm{MHz}$ (Avance III, 400). The Distortionless Enhancement by Polarization Transfer (DEPT) technique was used to determine peaks multiplicity. Samples were prepared by dissolving the polymer in deuterated water to a final concentration of $250 \mathrm{~g} / \mathrm{L}$.

Glass transition temperatures were obtained using Differential Scanning Calorimetry (DSC) measurements carried out on a DSC Discovery, TA Instruments, Inc. (USA). Samples were subjected to two heating scans with the following temperature program: first heating scan from -80 to $200^{\circ} \mathrm{C}$ at a heating rate of $5^{\circ} \mathrm{C} / \mathrm{min}$, subsequently, cooling to $-90^{\circ} \mathrm{C}$ at a heating rate of $10^{\circ} \mathrm{C} / \mathrm{min}$, and finally, a second heating scan from $-90^{\circ} \mathrm{C}$ to $400^{\circ} \mathrm{C}$ at a heating rate of $5^{\circ} \mathrm{C} / \mathrm{min}$. All scans were performed under nitrogen purge gas of $50 \mathrm{~mL} / \mathrm{min}$.

\section{Results and Discussion}

The analysis of results was statistically supported using a combinatorial experimental design with temperature and catalyst concentration as factors. Each factor was evaluated at three different levels, that is, temperatures of $130^{\circ} \mathrm{C}, 150^{\circ} \mathrm{C}$, and $170^{\circ} \mathrm{C}$ and catalyst concentrations of $1.5 \%(\mathrm{w} / \mathrm{w}), 3.35 \%$ $(\mathrm{w} / \mathrm{w})$, and $5.2 \%(\mathrm{w} / \mathrm{w})$. The response variables to analyze were polyglycerol hydroxyl number, molecular weight, and polydispersity. To determine polyglycerol morphology and thermal properties, a second experimental design was performed. This time the factors were evaluated at two different levels of temperature, $130^{\circ} \mathrm{C}$ and $150^{\circ} \mathrm{C}$, and catalyst concentrations, $1.5 \%(\mathrm{w} / \mathrm{w})$ and $5.2 \%(\mathrm{w} / \mathrm{w})$. Experimental test sequences were randomized and three replicates per level were taken. 
TABLE 1: Summary table of polyglycerol hydroxyl numbers obtained under different synthesis conditions at three temperatures and catalyst concentrations. Standard deviations were calculated based on triplicates. Three replicates per assay were taken.

\begin{tabular}{lcc}
\hline Temperature $\left({ }^{\circ} \mathrm{C}\right)$ & Catalyst \% (w/w) & $\begin{array}{c}\text { Hydroxyl number } \\
(\mathrm{mg} \mathrm{KOH} / \mathrm{g})\end{array}$ \\
\hline 130 & 1.5 & $610.4 \pm 20.5$ \\
130 & 3.35 & $441.2 \pm 4.2$ \\
130 & 5.2 & $566.1 \pm 12.4$ \\
150 & 1.5 & $525.8 \pm 28.4$ \\
150 & 3.35 & $506 \pm 23$ \\
150 & 5.2 & $390.1 \pm 13.3$ \\
170 & 1.5 & $413.1 \pm 23.8$ \\
170 & 3.35 & $318.1 \pm 29.5$ \\
170 & 5.2 & $370.6 \pm 20.7$ \\
\hline
\end{tabular}

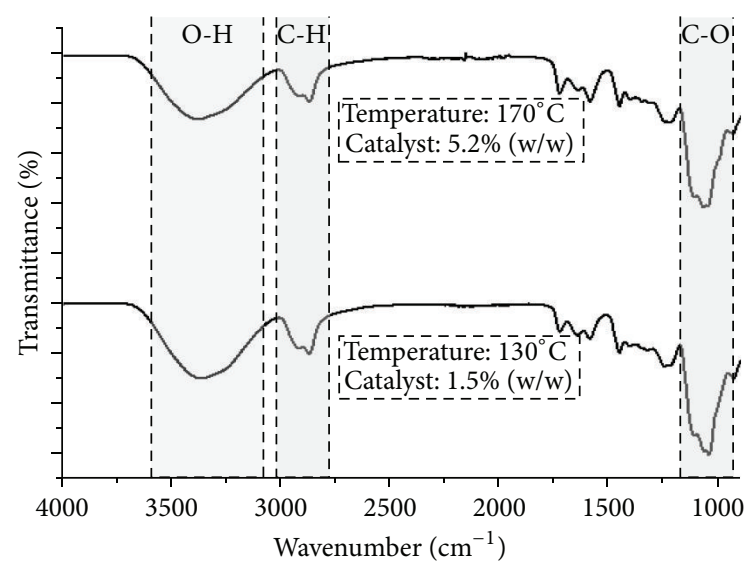

FIGURE 1: FT-IR spectra of the reaction products of glycerol polymerization performed at $130^{\circ} \mathrm{C}$ with a catalyst concentration of $1.5 \%(\mathrm{w} / \mathrm{w})$ and at $170^{\circ} \mathrm{C}$ with catalyst concentration of $5.2 \%(\mathrm{w} / \mathrm{w})$. The obtained spectra are similar to previously reported polyglycerol spectra [1].

Fourier transform infrared spectroscopy (FT-IR) analyses were conducted for all reaction products obtained from the experimental design. Results show that functional groups present in the reaction polymerization products are the same as polyglycerol functional groups identified in previous research studies [14]. For instance, $\mathrm{OH}$ stretching bands at $3000 \mathrm{~cm}^{-1}$ to $3600 \mathrm{~cm}^{-1}$ are related to polyglycerol terminal hydroxyl groups, broad alkyl stretching bands $(\mathrm{C}-\mathrm{H})$ are observed at 2883 and $2947 \mathrm{~cm}^{-1}$, and bands ranged from 950 to $1150 \mathrm{~cm}^{-1}$ (C-O stretching) are related to polyglycerol polyether chains. FT-IR spectra of two samples at different reaction conditions are shown in Figure 1. Those samples correspond to the products of glycerol polymerization performed at $130^{\circ} \mathrm{C}$ and $170^{\circ} \mathrm{C}$ at a catalyst concentration of $1.5 \%$ $(\mathrm{w} / \mathrm{w})$ and $5.2 \%(\mathrm{w} / \mathrm{w})$, respectively.

3.1. Polyglycerol Hydroxyl Number. Results from combinatorial experiments with hydroxyl number as response variable are shown in Table 1. It is shown that hydroxyl numbers

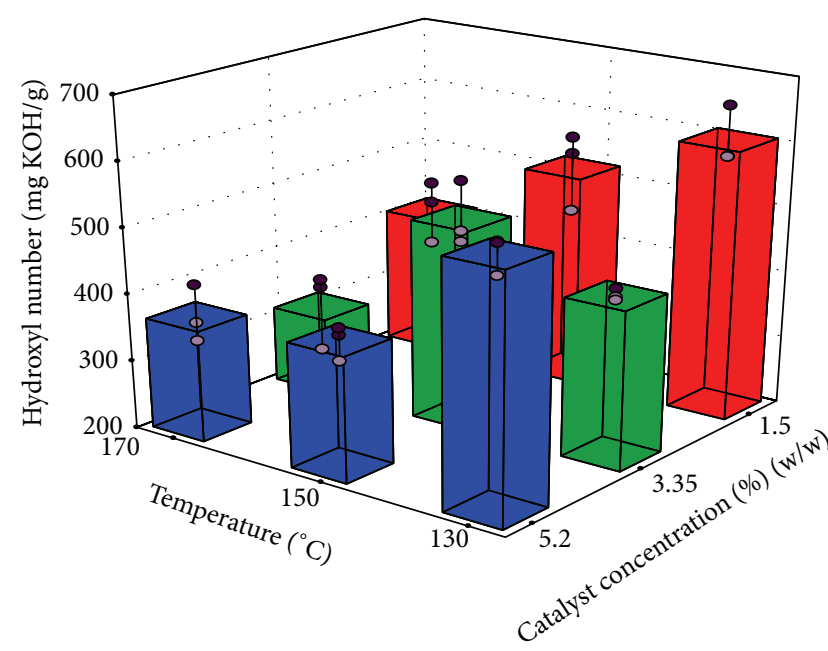

FIGURE 2: Temperature and catalyst concentration effect on polyglycerol hydroxyl number obtained from glycerol polymerization. Catalyst concentrations are shown: $1.5 \%(\mathrm{w} / \mathrm{w})$ in red, $3.35 \%(\mathrm{w} / \mathrm{w})$ in green, and $5.2 \%(\mathrm{w} / \mathrm{w})$ in blue.

of reaction products are lower than the initial hydroxyl number of glycerol, which is $1800[\mathrm{mg} \mathrm{KOH} / \mathrm{g}]$ [18]. This result is expected since homogeneous acid-catalyzed stepgrowth polymerization of glycerol proceeds by splitting a water molecule for each ether linkage formed decreasing the number of hydroxyls in the reaction product [14].

The experimental results show that polyglycerol functionality can be tuned with the reaction conditions because temperature $(P$ value $<0.0001)$, catalyst concentration $(P$ value: 0.0007$)$, and the interaction between these two factors $(P$ value: 0.0031$)$ have a significant effect on polyglycerol hydroxyl number. Temperature is the factor with the greatest effect followed by catalyst concentration and the interaction between factors, respectively; see Figure 2.

At fixed catalyst concentration of $1.5 \%(\mathrm{w} / \mathrm{w})$ and $5.2 \%$ $(\mathrm{w} / \mathrm{w})$, the polyglycerol hydroxyl number decreases as temperature increases. For instance, at catalyst concentration of $5.2 \%(\mathrm{w} / \mathrm{w})$, polyglycerol hydroxyl numbers at $130^{\circ} \mathrm{C}$, $150^{\circ} \mathrm{C}$, and $170^{\circ} \mathrm{C}$ were $566.1 \pm 12.4,390.1 \pm 13.3$, and $370.6 \pm 20.7 \mathrm{mg} \mathrm{KOH} / \mathrm{g}$, respectively. A different trend was found at fixed catalyst concentration of $3.35 \%(\mathrm{w} / \mathrm{w})$ where polyglycerol has the higher hydroxyl number at $150^{\circ} \mathrm{C}$ with $506.0 \pm 23 \mathrm{mg} \mathrm{KOH} / \mathrm{g}$ followed by $130^{\circ} \mathrm{C}$ and $170^{\circ} \mathrm{C}$ with hydroxyl numbers of $441.2 \pm 4.2$ and $318.1 \pm 29.5 \mathrm{mg} \mathrm{KOH} / \mathrm{g}$, respectively.

At fixed reaction temperatures of $130^{\circ} \mathrm{C}$ and $170^{\circ} \mathrm{C}$, polyglycerol has the lower hydroxyl number using a catalyst concentration of $3.35 \%(\mathrm{w} / \mathrm{w})$ with $441.2 \pm 4.2$ and $318.1 \pm$ $29.5 \mathrm{mg} \mathrm{KOH} / \mathrm{g}$, respectively, followed by catalyst concentration of $1.5 \%(\mathrm{w} / \mathrm{w})$ and $5.2 \%(\mathrm{w} / \mathrm{w})$ with hydroxyl numbers at $130^{\circ} \mathrm{C}$ of $610.4 \pm 20.5$ and $566.1 \pm 12.4 \mathrm{mg} \mathrm{KOH} / \mathrm{g}$ and hydroxyl numbers at $170^{\circ} \mathrm{C}$ of $413.1 \pm 23.8$ and $370.6 \pm 20.7 \mathrm{mg} \mathrm{KOH} / \mathrm{g}$, respectively. On the other hand, at fixed reaction temperature of $150^{\circ} \mathrm{C}$, as catalyst concentration increases, polyglycerol hydroxyl number decreases with hydroxyl numbers of $525.8 \pm$ $28.4,506 \pm 23$, and $390.1 \pm 13.3 \mathrm{mg} \mathrm{KOH} / \mathrm{g}$ using catalyst 


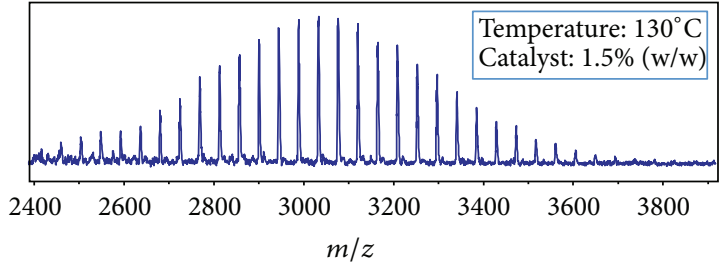

(a)

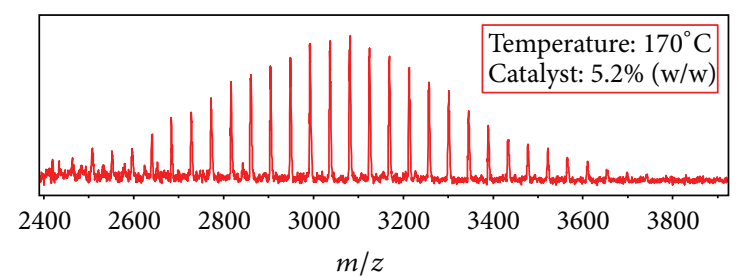

(b)

Figure 3: Polyglycerol molecular weight distributions determined with MALDI-TOF spectra of two samples. (a) Polyglycerol synthesized at $130^{\circ} \mathrm{C}$ and $1.5 \%(\mathrm{w} / \mathrm{w})$ catalyst concentration and (b) polyglycerol synthesized at $170^{\circ} \mathrm{C}$ and $5.2 \%(\mathrm{w} / \mathrm{w})$ catalyst concentration.

concentrations of 1.5\% (w/w), 3.35\% (w/w), and 5.2\% (w/w), respectively. Results show that catalyst concentration fails to produce the same trend effect on polyglycerol hydroxyl number at different levels of temperature since these two factors interact.

The decrease of hydroxyl number in the reaction products with respect to initial hydroxyl number of glycerol is due to chemical reactions that involve hydroxyl group reactions, such as etherification reactions and cyclization $[14,17]$. The results showed that temperature and catalyst concentration impact conversion of these reactions. Higher temperature or catalyst concentration increases reaction conversion resulting in a decrease of hydroxyl groups in reaction products. Results also showed that temperature and catalyst concentration are factors that interact; as a result, the impact of temperature on hydroxyl number varies depending on catalyst concentration.

3.2. Molecular Weight Distribution of Synthesized Polyglycerol. Temperature and catalyst concentrations do not have a significant effect on polyglycerol molecular weight and polydispersity. The number and weight average molecular weights, as well as the polydispersity of each treatment established by the combinatorial design, are shown in Table 2. Average values of molecular weights distributions ( $\mathrm{Mw}$ and $\mathrm{Mn}$ ), and polydispersity for all treatments were $2917.8 \mathrm{Da}, 2985.3 \mathrm{Da}$, and 1.023, respectively. Calculated molecular weights $(\mathrm{Mw})$ are in agreement with previously reported number average $\mathrm{Mw}$ of polyglycerol synthetized at $140^{\circ} \mathrm{C}$ and pressures below $26 \mathrm{kPa}$ [14], which is consistent with our findings regarding the fact that the number average $\mathrm{Mw}$ is not significantly affected by temperature and catalyst concentration. Figure 3 shows the MALDI-TOF mass spectra analysis of treatments with temperatures of $130^{\circ} \mathrm{C}$ and $170^{\circ} \mathrm{C}$ and catalyst concentrations of $1.5 \%(\mathrm{w} / \mathrm{w})$ and $5.2 \%(\mathrm{w} / \mathrm{w})$, respectively.

The fact that higher temperature and catalyst concentration decrease hydroxyl number of reaction product but do not decrease polyglycerol molecular weight and polydispersity suggests that temperature and catalyst concentration are affecting polyglycerol morphology. As will be shown in the next section, temperature and catalyst concentration affect reaction selectivity of glycerol hydroxyl groups. Higher temperature and catalyst concentration favor reaction of glycerol secondary hydroxyl group forming polyglycerol branched structures.
TABLE 2: Summary table of polydispersity, number, and weight average molecular weights of polyglycerol synthesized at three different temperatures $\left(130,150\right.$, and $\left.170^{\circ} \mathrm{C}\right)$ and catalyst concentrations $1.5 \%$ $(\mathrm{w} / \mathrm{w}), 3.35 \%(\mathrm{w} / \mathrm{w})$, and $5.2 \%(\mathrm{w} / \mathrm{w})$.

\begin{tabular}{lcccc}
\hline Temperature $\left({ }^{\circ} \mathrm{C}\right)$ & $\begin{array}{c}\text { Catalyst } \\
\%(\mathrm{w} / \mathrm{w})\end{array}$ & $\mathrm{Mw}(\mathrm{Da})$ & $\mathrm{Mn}(\mathrm{Da})$ & $\mathrm{PD}$ \\
\hline 130 & 1.5 & 2987.2 & 2919.1 & 1.023 \\
130 & 3.35 & 2986.5 & 2917.6 & 1.024 \\
130 & 5.2 & 2976.2 & 2908.9 & 1.023 \\
150 & 1.5 & 2978.2 & 2910.3 & 1.023 \\
150 & 3.35 & 2978.3 & 2911.3 & 1.023 \\
150 & 5.2 & 3012.4 & 2943.2 & 1.023 \\
170 & 1.5 & 2991.1 & 2924.5 & 1.023 \\
170 & 3.35 & 2975.6 & 2908.2 & 1.023 \\
170 & 5.2 & 2982.5 & 2917.2 & 1.022 \\
\hline
\end{tabular}

3.3. Polyglycerol Morphology. Branched structures, terminal units, and polyether chains within the polyglycerol structure, which ultimately define polyglycerol morphology, were identified in the polyglycerol samples obtained under different synthesis conditions and analyzed using the ${ }^{13} \mathrm{C}$ NMR spectroscopy technique (Table 3). Peak analysis between quantitative ${ }^{13} \mathrm{C}$ NMR and DEPT spectra was made to establish polyglycerol morphology. The ${ }^{13} \mathrm{C}$ NMR spectra region from 60 to $64 \mathrm{ppm}$ indicates the presence of $-\mathrm{CH}_{2} \mathrm{OH}$ carbons of polyglycerol terminal units, which are primary hydroxyl groups; the signal region from 68 to $73 \mathrm{ppm}$ indicates the presence of $-\mathrm{CHOH}$ - carbons, which are pending hydroxyl groups; the region from 72 to $73 \mathrm{ppm}$ indicates $-\mathrm{CH}_{2}-\mathrm{O}$ carbons, which are polyether chains; and that from 74 to $82 \mathrm{ppm}$ indicates the presence of - $\mathrm{CH}-\mathrm{O}$ - carbons related to the beginning of branched chains [12,17]. Table 4 shows the functional groups found at specific peak intervals at each particular temperature and catalyst concentration. An example of a quantitative ${ }^{13} \mathrm{C}$ NMR spectrum performed at $130^{\circ} \mathrm{C}$ and $1.5 \%(\mathrm{w} / \mathrm{w})$ catalyst concentration is shown in Figure 4 where the ${ }^{13} \mathrm{C}$ NMR spectrum regions analyzed are highlighted.

The results of polyglycerol morphology were calculated taking the relative area under spectra signals in the spectra region that identify each kind of carbon described in Table 4 .

The results show that temperature, catalyst concentration, and their interaction have a significant effect on polyglycerol 
TABLE 3: Temperature $\left({ }^{\circ} \mathrm{C}\right)$, catalyst concentration $\%(\mathrm{w} / \mathrm{w})$, and relative area under spectra region used to quantify and identify different polyglycerol carbons. All experiments were carried out in duplicate.

\begin{tabular}{|c|c|c|c|c|}
\hline $\begin{array}{l}\text { Temperature } \\
\left({ }^{\circ} \mathrm{C}\right)\end{array}$ & $\begin{array}{l}\text { Catalyst \% } \\
(\mathrm{w} / \mathrm{w})\end{array}$ & $\begin{array}{c}-\mathrm{CH}_{2} \mathrm{OH} \text { carbons } \\
60-64 \mathrm{ppm} \\
\text { terminal units } \\
(\%)\end{array}$ & $\begin{array}{c}-\mathrm{CHOH}-,-\mathrm{CH}_{2}-\mathrm{O}-\text { carbons } \\
68-73 \mathrm{ppm} \\
\text { polyether chains and pending } \\
\text { hydroxyl groups } \\
(\%)\end{array}$ & $\begin{array}{c}\text {-CH-O- carbons } \\
\text { 74-82 ppm branching } \\
(\%)\end{array}$ \\
\hline 130 & 1.5 & $46.1 \pm 0.5$ & $51.8 \pm 1.4$ & $2.0 \pm 0.9$ \\
\hline 130 & 5.2 & $50.1 \pm 0.3$ & $47.7 \pm 0.8$ & $2.2 \pm 0.5$ \\
\hline 150 & 1.5 & $30.6 \pm 1.2$ & $61.1 \pm 0.6$ & $8.3 \pm 0.6$ \\
\hline 150 & 5.2 & $14.2 \pm 0.0$ & $55.9 \pm 0.3$ & $29.9 \pm 0.3$ \\
\hline
\end{tabular}

TABLE 4: Model of glycerol polymerization growing chain containing linear, branched, and cyclic segments and their carbons assignments by ${ }^{13}$ C NMR (see also Scheme 1) [12, 14, 17].

\begin{tabular}{|c|c|c|c|}
\hline \multicolumn{4}{|c|}{ Carbon type $\left(\delta{ }^{13} \mathrm{C}\right.$ in ppm $)$} \\
\hline$-\mathrm{CH}_{2} \mathrm{OH}$ & $-\mathrm{CHOH}-$ & $-\mathrm{CH}_{2}-\mathrm{O}-$ & $-\mathrm{CH}-\mathrm{O}-$ \\
\hline $\begin{array}{l}60-64 \text { ppm } \\
\text { Polyglycerol terminal units } \\
\text { (primary hydroxyl groups) }\end{array}$ & $\begin{array}{c}68-73 \mathrm{ppm} \\
\text { pendant hydroxyl groups }\end{array}$ & $\begin{array}{l}72-73 \mathrm{ppm} \\
\text { polyether chains }\end{array}$ & $\begin{array}{l}74-82 \text { ppm } \\
\text { branching }\end{array}$ \\
\hline C-1, C-9, C-17', C-27, and C-27' & $\mathrm{C}-2, \mathrm{C}-6, \mathrm{C}-16^{\prime}, \mathrm{C}-16^{\prime \prime}$, and C-26 & 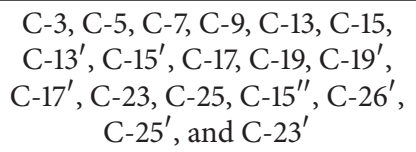 & $\begin{array}{c}\text { C-10, C-12, C-20, and } \\
\text { C-22 }\end{array}$ \\
\hline
\end{tabular}<smiles>OCC(O)COCC(O)COCC(CO)OC(COCC(O)COCC(O)CO)COCC(COCC(O)CO)OCC(O)COCC(O)CO</smiles>

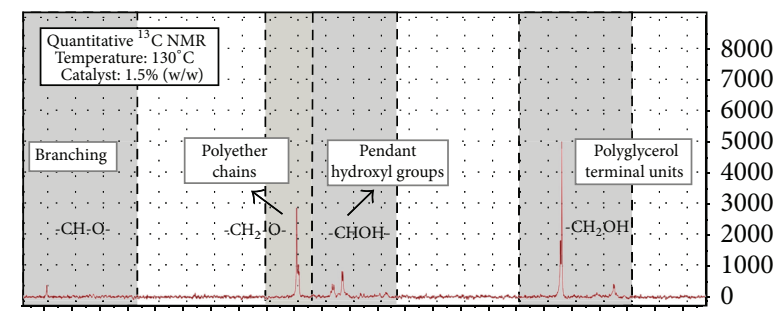

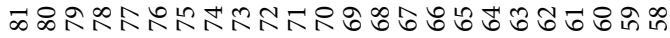
$f 1(\mathrm{ppm})$

FIgURE 4: Quantitative ${ }^{13} \mathrm{C}$ NMR spectra of the polyglycerol synthesized at $130^{\circ} \mathrm{C}$ and $1.5 \%(\mathrm{w} / \mathrm{w})$ catalyst concentrations.

morphology $(P$ value $<0.0001)$. This result suggests that these factors impact reaction selectivity of hydroxyl groups. The increment of these factors favors secondary hydroxyl group reaction varying polyglycerol morphology. Temperature is the factor with the greatest effect on polyglycerol morphology. At fixed catalyst concentration of $5.2 \%(\mathrm{w} / \mathrm{w})$, as temperature increases from 130 to $150^{\circ} \mathrm{C}$, polyglycerol terminal units decrease from 50.1 to $14.2 \%$, polyglycerol polyether chains increase from 47.7 to $55.9 \%$, and branching increases from 2.2 to $29.86 \%$, respectively. Same trend is observed at fixed catalyst concentration of $1.5 \%(\mathrm{w} / \mathrm{w})$; however, the impact of temperature on polyglycerol morphology diminishes at lower catalyst concentration revealing the existence of an interaction between these two factors. At fixed temperature of $130^{\circ} \mathrm{C}$, the increment of catalyst concentration from 1.5 to $5.2 \%(\mathrm{w} / \mathrm{w})$ has a slight effect on polyglycerol terminal units (from $46.1 \%$ to $50.1 \%$ ), polyether chains (from $51.8 \%$ to $47.7 \%$ ), and branching (from $2 \%$ to $2.2 \%$ ). On the other hand, at fixed temperature of $150^{\circ} \mathrm{C}$, the increment of catalyst concentration has a considerable effect on polyglycerol terminal units (from $30.6 \%$ to $14.2 \%$ ), polyether chains (from $61.1 \%$ to $55.9 \%$ ), and branching (from $8.3 \%$ to $29.9 \%$ ). These changes in the impact of catalyst concentration as a function of temperature are due to interaction between factors. 


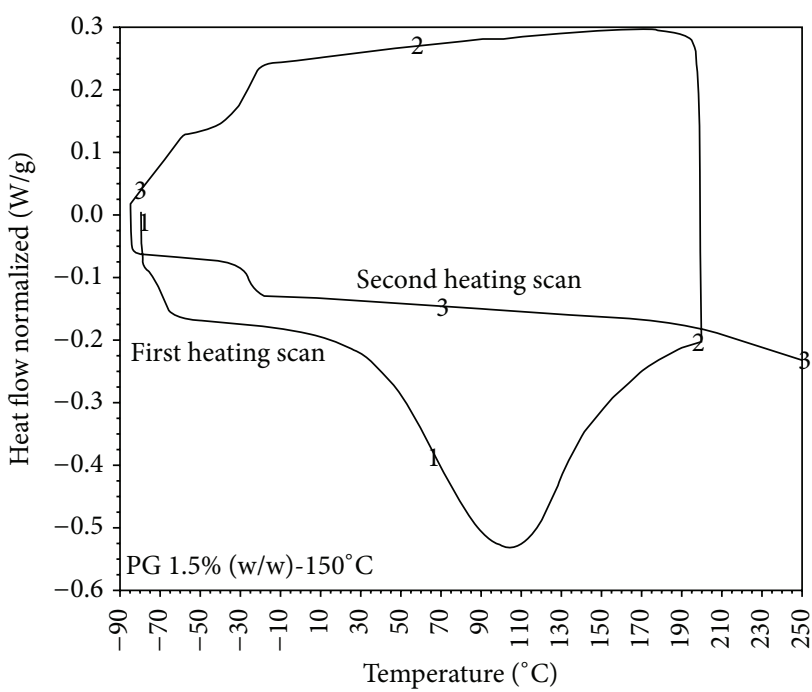

(a)

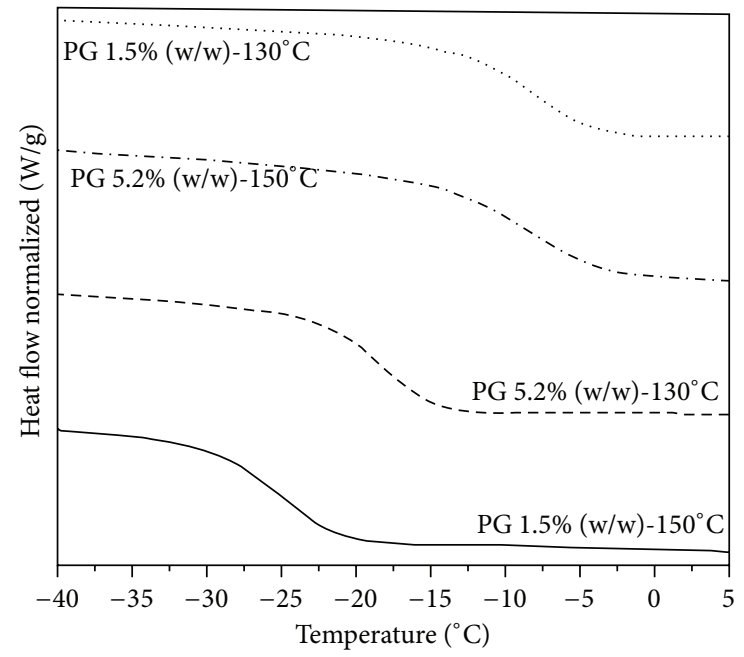

(b)

FIGURE 5: (a) First and second heating scan DSC results for polyglycerol synthetized with catalyst concentration of $1.5 \%$ (w/w) and temperature of $150^{\circ}$ C. (b) Polyglycerol glass transition temperatures found in the second heating scan.

3.4. Polyglycerol Glass Transition Temperature. Polyglycerol glass transition temperature marks the change from glassy or energy-elastic state to a rubbery or entropy drivenelastic state. Thus, the knowledge of this polyglycerol thermal property is essential in the selection of this material for various applications.

Glass transition temperatures were determined using DSC experimental procedure that was performed in two heating scans. The first scan was performed to reveal information about the current conditions of polyglycerol. For instance, processing influences an effect of attached water to the polar hydroxyl groups on thermal properties [19]. After cooling, a second heating scan was performed to determine particular properties of polyglycerol without the influence of volatile substances and processing.

In the first heating scan, glass transition temperatures were observed at temperatures below $-50^{\circ} \mathrm{C}$. As heating progresses, water begins to evaporate at around $30^{\circ} \mathrm{C}$ causing an endothermic change in the heating curve. The particular strong bond between water and polyglycerol hydroxyl groups makes the diffusion of water through polyglycerol difficult, resulting in an endothermic change in the heating curve that went up to $200^{\circ} \mathrm{C}$. After cooling, during the second heating scan, glass transition temperatures increased and the endothermic change in the heating curve disappeared.

Statistical analysis suggests that polyglycerol glass transition temperature is significantly affected by catalyst concentration ( $P$ value: 0.0002$)$, temperature ( $P$ value: 0.0002$)$, and the interaction between these two factors $(P$ value: $<$ 0.0001). The interaction between temperature and catalyst concentration is the factor with the greatest effect. For instance, at fixed catalyst concentration of $1.5 \%(\mathrm{w} / \mathrm{w})$, an increment in temperature from $130^{\circ} \mathrm{C}$ to $150^{\circ} \mathrm{C}$ caused the glass transition temperature to decrease from $-8.6^{\circ} \mathrm{C}$ to $-25.3^{\circ} \mathrm{C}$. On the other hand, at catalyst concentration of $5.2 \%$ $(\mathrm{w} / \mathrm{w})$ and the same temperature change from $130^{\circ} \mathrm{C}$ to $150^{\circ} \mathrm{C}$ the glass transition temperature increased from $-18.6^{\circ} \mathrm{C}$ to $-8^{\circ} \mathrm{C}$. Similar trend was found at fixed temperatures of $130^{\circ} \mathrm{C}$ and $150^{\circ} \mathrm{C}$; varying catalyst concentration from $1.5 \%(\mathrm{w} / \mathrm{w})$ to $5.2 \%(\mathrm{w} / \mathrm{w})$ at $130^{\circ} \mathrm{C}$ caused the glass transition temperature to decrease, whereas varying catalyst concentration from $1.5 \%$ $(\mathrm{w} / \mathrm{w})$ to $5.2 \%(\mathrm{w} / \mathrm{w})$ at $150^{\circ} \mathrm{C}$ caused the glass transition temperature to increase showing interaction between factors.

Polyglycerol glass transition temperature depends on both, polymer branching structure and the amount of $-\mathrm{OH}$ hydrophilic groups. It has been reported that an increase of polymer branching leads a restriction of segmental mobility which increases glass transition temperature [20]. Similarly, hydrophilic groups in the polymer chemical structure, like $\mathrm{OH}$, capable of hydrogen bonding affect glass transition temperature $[21,22]$. Since catalyst concentration and temperature influence polyglycerol hydroxyl number and branching in an opposite way, when polyglycerol hydroxyl number decreases branching increases, there is a competition in the impact of hydroxyl number and branching on polyglycerol glass transition temperature. For instance, at fixed catalyst concentration of $5.2 \%$, a change of temperature from $130^{\circ} \mathrm{C}$ to $150^{\circ} \mathrm{C}$ decreases polyglycerol hydroxyl number from $566 \mathrm{mg} \mathrm{KOH} / \mathrm{g}$ to $390 \mathrm{mg} \mathrm{KOH} / \mathrm{g}$ but increases polyglycerol branching from $2.2 \%$ to $29.9 \%$. In this case, polyglycerol branching has more impact on glass transition temperature since it increases from $-18^{\circ} \mathrm{C}$ to $-8^{\circ} \mathrm{C}$. On the other hand, at fixed temperature of $-130^{\circ} \mathrm{C}$, a change of catalyst concentration from $1.5 \%$ to $5.2 \%$ decreases polyglycerol hydroxyl number from $610 \mathrm{mg} \mathrm{KOH} / \mathrm{g}$ to $566 \mathrm{mg} \mathrm{KOH} / \mathrm{g}$ and the change of polyglycerol branching is negligible from $2 \%$ to $2.2 \%$. Thus, in this case, the polyglycerol hydroxyl number has more impact on decreasing polyglycerol glass transition temperature from $-8.6^{\circ} \mathrm{C}$ to $-18.6^{\circ} \mathrm{C}$, as shown in Figure 5 . 


\section{Conclusions}

New insights have been obtained regarding the effect of synthesis conditions of production of polyglycerol from glycerol on the final polyglycerol morphology, molecular weight, polydispersity, thermal properties, and functionality. Temperature and catalyst concentration of synthesis enable the synthesis of polyglycerol with specific fundamental parameters that determine polyglycerol final applications. The increase of temperature of synthesis decreases polyglycerol -OH terminal units, increases polyglycerol polyether chains and pending hydroxyl groups, increases polyglycerol branching, and decreases polyglycerol hydroxyl number. In general, the impact of temperature of synthesis on morphology and functionality escalates significantly at higher catalyst concentration. Changes in polyglycerol morphology and functionality affect glass transition temperature due to changes in polyglycerol branching degree and hydroxyl number. Furthermore, polyglycerol molecular weight and polydispersity were not significantly affected by variations in temperature and catalyst concentration during the process of synthesis.

\section{Conflict of Interests}

The authors declare that there is no conflict of interests regarding the publication of this paper.

\section{Acknowledgments}

This study is supported by the Office of the Research and Community Outreach Provost at Universidad Industrial de Santander (UIS) through a research grant (code 5459), the agreement of cooperation (code 0727) between UIS University and Colciencias, and the agreement of cooperation (code 65061538329) between Corasfaltos and Colciencias. The Mass Spectroscopy and Nuclear Magnetic Resonance laboratories of UIS University are also gratefully acknowledged. The authors thank Drs. Andrea Garzón and Perla Balbuena for carefully reviewing this paper.

\section{References}

[1] S. Salehpour, C. J. Zuliani, and M. A. Dubé, "Synthesis of novel stimuli-responsive polyglycerol-based hydrogels," European Journal of Lipid Science and Technology, vol. 114, no. 1, pp. 92-99, 2012.

[2] X. Yang and L. Liu, "Synthesis and characterization of novel polyglycerol hydrogels containing L-lactic acid groups as pendant acidic substituents: $\mathrm{pH}$-responsive polyglycerol-based hydrogels," Journal of Applied Polymer Science, vol. 112, no. 6, pp. 3209-3216, 2009.

[3] M. H. M. Oudshoorn, R. Rissmann, J. A. Bouwstra, and W. E. Hennink, "Synthesis and characterization of hyperbranched polyglycerol hydrogels," Biomaterials, vol. 27, no. 32, pp. 5471$5479,2006$.

[4] I. Gülseren and M. Corredig, "Interactions between polyglycerol polyricinoleate (PGPR) and pectins at the oil-water interface and their influence on the stability of water-in-oil emulsions," Food Hydrocolloids, vol. 34, pp. 154-160, 2014.
[5] K. Matsumiya, Y. Takahashi, K. Nakanishi, N. Dotsu, and Y. Matsumura, "Diglycerol esters of fatty acids promote severe coalescence between protein-stabilized oil droplets by emulsifier-protein competitive interactions," Food Hydrocolloids, vol. 42, no. 3, pp. 397-402, 2014.

[6] V. S. Thengarai, J. Keilitz, and R. Haag, "Hyperbranched polyglycerol supported ruthenium catalysts for ring-closing metathesis," Inorganica Chimica Acta, vol. 409, pp. 179-184, 2014.

[7] J.-P. Boudou, M.-O. David, V. Joshi, H. Eidi, and P. A. Curmi, "Hyperbranched polyglycerol modified fluorescent nanodiamond for biomedical research," Diamond and Related Materials, vol. 38, pp. 131-138, 2013.

[8] K. Höger, T. Becherer, W. Qiang, R. Haag, W. Frieß, and S. Küchler, "Polyglycerol coatings of glass vials for protein resistance," European Journal of Pharmaceutics and Biopharmaceutics, vol. 85, no. 3, pp. 756-764, 2013.

[9] D. Steinhilber, M. Witting, X. Zhang et al., "Surfactant free preparation of biodegradable dendritic polyglycerol nanogels by inverse nanoprecipitation for encapsulation and release of pharmaceutical biomacromolecules," Journal of Controlled Release, vol. 169, no. 3, pp. 289-295, 2013.

[10] M. Ayoub and A. Z. Abdullah, "Critical review on the current scenario and significance of crude glycerol resulting from biodiesel industry towards more sustainable renewable energy industry," Renewable and Sustainable Energy Reviews, vol. 16, no. 5, pp. 2671-2686, 2012.

[11] W. Daniel, S.-E. Stiriba, and F. Holger, "Hyperbranched polyglycerols: from the controlled synthesis of biocompatible polyether polyols to multipurpose applications," Accounts of Chemical Research, vol. 43, no. 1, pp. 129-141, 2010.

[12] A. Sunder, R. Hanselmann, H. Frey, and R. Mülhaupt, "Controlled synthesis of hyperbranched polyglycerols by ringopening multibranching polymerization," Macromolecules, vol. 32, no. 13, pp. 4240-4246, 1999.

[13] G. Rokicki, P. Rakoczy, P. Parzuchowski, and M. Sobiecki, "Hyperbranched aliphatic polyethers obtained from environmentally benign monomer: glycerol carbonate," Green Chemistry, vol. 7, no. 7, pp. 529-539, 2005.

[14] S. Salehpour and M. A. Dubé, "Towards the sustainable production of higher-molecular-weight polyglycerol," Macromolecular Chemistry and Physics, vol. 212, no. 12, pp. 1284-1293, 2011.

[15] A. Martin and M. Richter, "Oligomerization of glycerol-a critical review," European Journal of Lipid Science and Technology, vol. 113, no. 1, pp. 100-117, 2011.

[16] M. V. Sivaiah, S. Robles-Manuel, S. Valange, and J. Barrault, "Recent developments in acid and base-catalyzed etherification of glycerol to polyglycerols," Catalysis Today, vol. 198, no. 1, pp. 305-313, 2012.

[17] S. Cassel, C. Debaig, T. Benvegnu et al., "Original synthesis of linear, branched and cyclic oligoglycerol standards," European Journal of Organic Chemistry, vol. 2001, no. 5, pp. 875-896, 2001.

[18] M. L. Mamiński, R. Szymański, P. Parzuchowski, A. Antczak, and K. Szymona, "Hyperbranched polyglycerols with bisphenol A core as glycerol-derived components of polyurethane wood adhesives," BioResources, vol. 7, no. 2, pp. 1440-1451, 2012.

[19] J. Gupta, C. Nunes, and S. Jonnalagadda, "A molecular dynamics approach for predicting the glass transition temperature and plasticization effect in amorphous pharmaceuticals," Molecular Pharmaceutics, vol. 10, no. 11, pp. 4136-4145, 2013. 
[20] Q. Zhu, J. Wu, C. Tu et al., "Role of branching architecture on the glass transition of hyperbranched polyethers," The Journal of Physical Chemistry B, vol. 113, no. 17, pp. 5777-5780, 2009.

[21] A. Khalyavina, L. Häußler, and A. Lederer, "Effect of the degree of branching on the glass transition temperature of polyesters," Polymer, vol. 53, no. 5, pp. 1049-1053, 2012.

[22] C. Xi, L. Sztandera, and H. M. Cartwright, "A neural network approach to prediction of glass transition temperature of polymers," International Journal of Intelligent Systems, vol. 23, no. 1, pp. 22-32, 2008. 

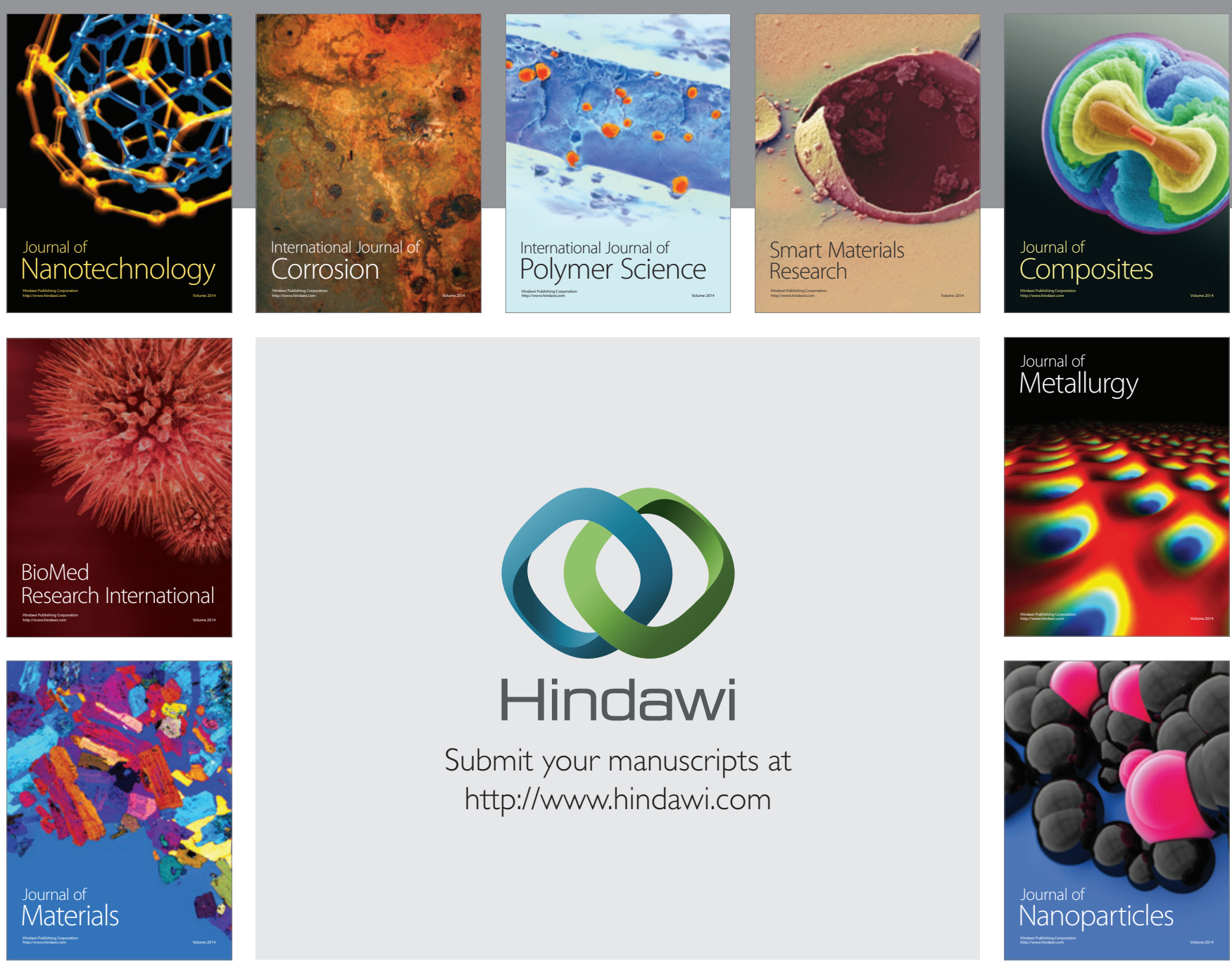

Submit your manuscripts at http://www.hindawi.com
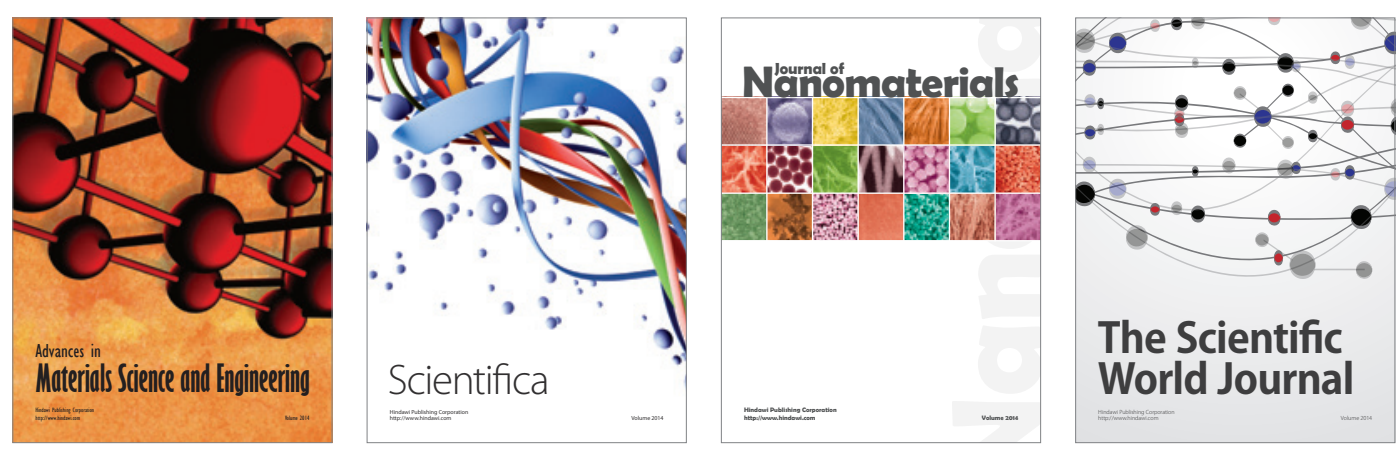

\section{The Scientific World Journal}
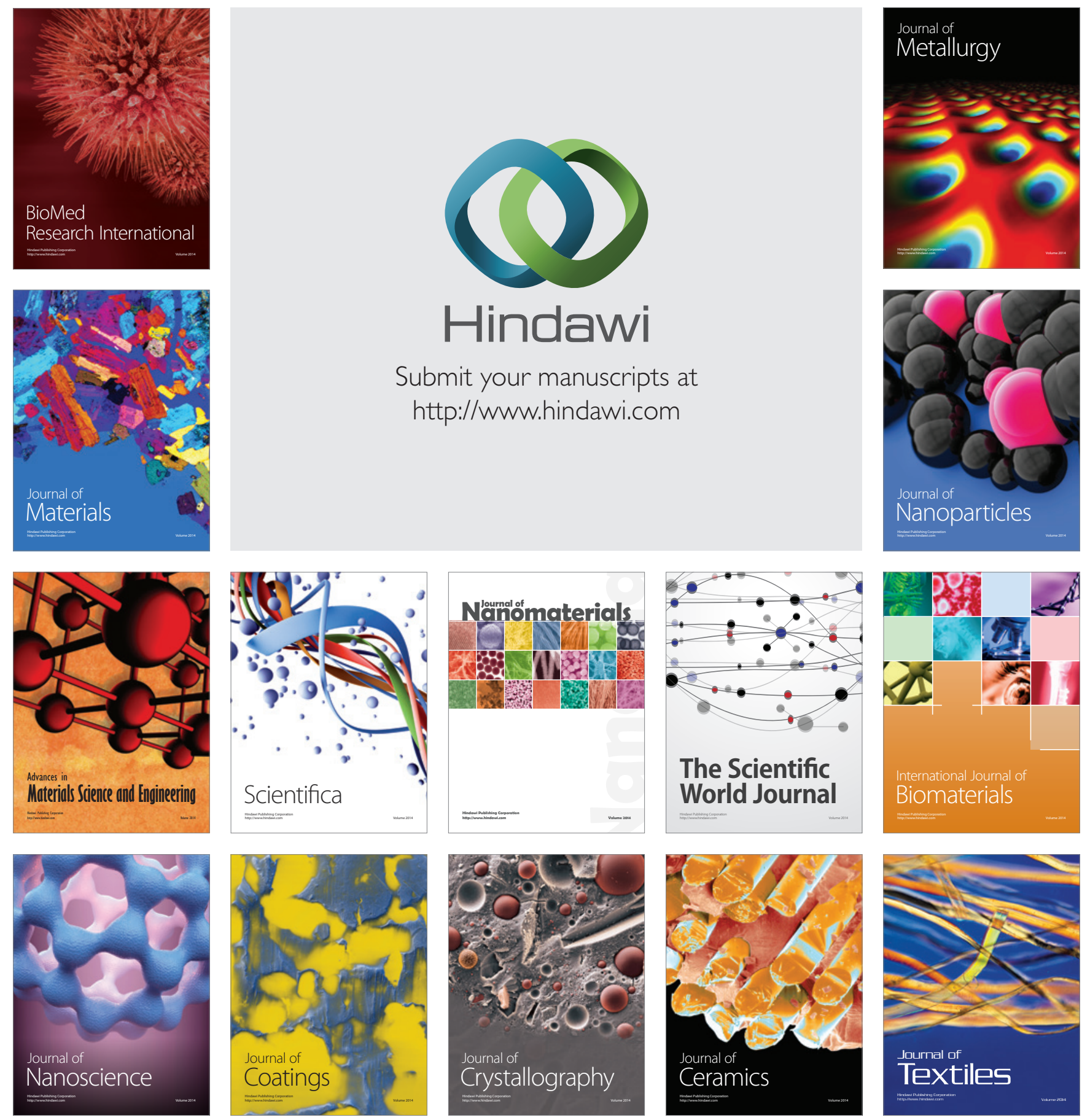